\title{
Ethical Issues: The Multi-Centre Low-Risk Ethics/Governance Review Process and AMOSS
}

\author{
Abstract \\ Objective: To describe the ethics/governance review pathway undertaken by the Australasian \\ Maternity Outcomes Surveillance System (AMOSS), a multi-centre population health study \\ with minimal ethical impact.
}

Method: Prospective, descriptive study during 2009-11 of the governance/ethical review processes and associated workload to gain approval for Australian and New Zealand (NZ) maternity units with more than 50 births per year $(\mathrm{n}=303)$ to participate in AMOSS.

Results: Review processes ranged from a single application for $24 \mathrm{NZ}$ sites, a single application for eligible hospitals in two Australian states, full Health Research Ethics Committee (HREC) applications for individual hospitals, through to simple letters of support. As of May 2011, 43 full/expedited ethics applications, 135 site governance applications and 139 letters of support requests were made over 26 months, involving an estimated 3,226 hours by AMOSS staff/investigators, and an associated resource burden by participating sites, to obtain approval to receive non-identifiable data from 285 hospitals.

Conclusion: The research that AMOSS conducts is critical for identifying the incidence of conditions that cause rare and serious maternal morbidity. Yet the highly variable ethical approval processes required to implement this bi-national study have been excessively repetitive and burdensome. The nature of this process jeopardises timely, efficient research project implementation, without corresponding benefits to research participants. The resource burden to establish research governance for a national surveillance of severe maternal morbidity in ANZ confirms the urgent need for the Harmonisation of Multi-centre Ethical Review (HoMER) to further streamline ethics/ governance review processes for multi-centre research.

Keywords: Ethical review; ethics committees, multi-centre studies; research governance, epidemiological studies. 


\section{Introduction}

The challenge to efficient implementation of ethics/governance review processes for low-risk research conducted on multiple sites has long been recognised. In 2006, the Australian National Health and Medical Research Council (NHMRC) facilitated the development of a national single ethical review process for collaborative multi-centre studies: the HoMER initiative(1). The objectives of HoMER include the elimination of unnecessary duplication and delays in ethics reviews while promoting ethically sound research(2).

Whilst there has been much discussion about ethical reviews since the implementation of HoMER, the application process remains challenging to researchers and clinicians.(3-8) This paper describes the experience of one study across Australia and New Zealand (ANZ). The Australasian Maternity Outcomes Surveillance System (AMOSS) project is significant because of the volume and range of sites involved. The aim of this study was to examine the approval processes and workload required to implement AMOSS.

\section{Methods}

A prospective, descriptive study examined the ethical review and research governance processes required to obtain approval for AMOSS data collection throughout ANZ and the associated burden of this process.

\section{Study setting: the AMOSS project}

AMOSS studies the epidemiology of serious conditions of pregnancy. Maternal mortality is rare in Australasia, and there is a paucity of data available on the incidence, risk factors and outcomes of severe morbidity in pregnancy.

AMOSS is developing a bi-national perspective on these conditions and associated interventions. It provides an invaluable nexus of researchers, clinicians and a research infrastructure supported by over 300 ANZ maternity units. The research describes the burden of rare, severe events in pregnancy and raises awareness of perinatal morbidity. Findings will provide the incidence of severe maternal morbidity on specified conditions for the first time in ANZ, with no reliable data available from routine data sources(9). Additionally, AMOSS will develop an evidence base to inform clinical guidelines for relevant maternity services(10). Eligible maternity units contribute non-identified data via a secure web-based survey system.

Phase I of the project included consultation, establishment of governance, system development, site recruitment and extension to NZ. The current Phase II involves data collection, analysis, evaluation and multi-centre collaboration. AMOSS participation covers over $96 \%$ (Australia) and 100\% (NZ) births in eligible sites.

The research (NHMRC-funded in Australia) is considered low-risk research, and no consent is required by participants. However, under NHMRC guidelines of research involving fetuses and pregnant women, it was deemed that HREC ethical approval process should be followed(11).

Obtaining approval to collect data involves two stages. Ethical reviews address principles of conduct in health research. Governance reviews address issues related to the individual site's agreement to participate, including quality, safety, risk management, financial management and accountability(12). Prior to HoMER, ethical and research governance reviews were generally collapsed into one process, with both conducted by the reviewing institution's 
HREC. One of the consequences of HoMER has been the separation of this process, as a 'site appraisal' cannot be done by a remote $\operatorname{HREC}(13)$.

\section{Participants and recruitment procedure}

All maternity units in ANZ with more than 50 births per year were invited to participate in AMOSS using a variety of methods. In Australia, in-principle support was followed by the required application. In NZ, the National Coordinator of its Perinatal and Maternal Mortality Review Committee (PMMRC) worked with all 24 eligible sites (covering 20 District Health Boards [DHBs]) to designate data coordinators.

\section{Data collection method and variables}

A purpose-built database was established to manage application processes. Variables included HREC, type/s of applications required, policy variations, history and submission/approval details. Process categories for ethics/research governance were defined along with additional site requirements. A log system recorded communications relating to the review and the length of time from submission by AMOSS to approval by HREC.

\section{Results}

There were significant variations in the application processes between NZ and Australia, and additionally by states and territories (Table 2).

\section{Ethics application processes}

AMOSS first submitted an ethics application to the University of New South Wales (UNSW) as its administering institution, and approval was granted in March 2009 for a five year period. NSW Population Health and Health Services Research Ethics Committee, accredited to provide single ethical review of research proposals conducted within the New South Wales (NSW) public health system, then approved the AMOSS study in April 2009 for the duration of the research.

The National Ethics Application Form (NEAF) is a key tool in the HoMER system. NEAF is implemented in NSW, Queensland and Victoria, but may also be accepted by HRECs in other States. HRECs in Victoria accepted NEAF and/or Core Module One, with an accompanying Victorian Specific Module which addresses State-specific legislative requirements(14). In Queensland, NEAF and low-risk ethics applications were variously submitted according to how AMOSS was categorised (this system has changed since July 2010 - see below). Victoria and Queensland also had a number of sites that granted approval based on prior ethics approval by local governance committees. Most private hospitals required an ethics review by their own clinical governance committee although two large groups accepted prior HREC approval, followed by site-specific support.

The University of Tasmania, covering all public and private hospitals, endorsed AMOSS under its policy of prior approval from an NHMRC-registered HREC. The Northern Territory gave approval for public hospital sites based on two NEAF applications. In Western Australia, either full hospital-specific and/or country Area Health Service (AHS) ethics applications were required, or it was considered a Quality Activity. The Australian Capital Territory required a NEAF application for each hospital. In South Australia, discussion with a Department of Health representative and Perinatal Practice Workgroup members resulted in state-wide endorsement of AMOSS, followed by site-based e-mail agreements. One SA private hospital additionally required a full ethics application. 
Submission processes varied markedly. Hard copy ethics applications were required by 36 HRECS. Of these, 24 HRECs required multiple (range 2-26) hard copies of the application. Over 8,000 printed pages have been required to May 2011. Seven HRECs accepted electronic submission either via email or the Online Forms website(15).

\section{New Zealand}

In NZ, AMOSS data is monitored through the AMOSS Working Group under the directive of the Perinatal and Maternal Mortality Review Committee (PMMRC) established under the NZ Public Health and Disability Act 2000. The PMMRC submitted a single application for an Expedited Review of Observational Studies to the National Ethics Advisory Committee (NEAC) and ethical approval AMOSS across all 24 NZ sites was granted until 2014. The entire ethics process required an estimated ten hours(16).

Table 2 details the number of application processes according to jurisdiction and HREC within Australia, and compares to NZ and the UK counterpart of AMOSS, the UK Obstetric Surveillance System (UKOSS).

\section{Research governance}

The second stage of approval relates to research governance issues, specifically addressing resources, budget and facilities at individual hospitals. Of those 135 HRECs or hospital groups that required a site governance application, five required Site Specific Assessments (SSAs) or other governance application for each hospital, while the remainder requested a single application for all sites, with individual hospitals ratifications. Four sites were uncertain of approval processes due to regional restructuring. Two HRECs required original signatures from six researchers across Australia and the United Kingdom on a previously approved NEAF for the site application.

Variation was significant between but also within HRECs. Staff turnover resulted in policy changes and attendant delays. One application for an SSA application (to an HREC where AMOSS had prior site approval) took 111 days from submission to approval. Additionally, there were large variations in the length of ethics approval granted by HRECs (range nine to 58 months, median 36 months). Separate annual reporting is required by most HRECs and private hospital groups.

Table 1 gives a summary of steps required to complete the AMOSS ethics/governance application process, and comments on the process.

\section{Current status}

Ethical/governance approval to participate in AMOSS has been obtained for 261 out of 279 eligible maternity units in Australia and all 24 eligible units in NZ By May 2011, the application process for AMOSS had taken 26 months, an estimated 92 weeks' person-time and almost $40 \%$ of the planned project lifetime. Table 3 details the estimated time involved in completion of the application processes.

\section{Discussion}

The review process for AMOSS has hampered much needed national research into severe conditions in pregnancy. The 2007 National Statement on Ethical Conduct in Human Research emphasises the need to eliminate any unnecessary duplicative processes in the conduct of ethical reviews(11). Yet our experience demonstrated this policy was not followed in many instances, with inconsistencies between jurisdictions, AHSs, HRECs and individual 
sites perpetuating unnecessary duplication. Figure 2A illustrates the experience of AMOSS in obtaining ethics/governance approval, and contrasts to the NHMRC (Figure 1) model. Figure 2B depicts a suggested model for low-risk multi-centre research.

Kim et al estimate that over half of review board costs are devoted to evaluating low-risk research(17). It is likely that an equivalent cost would apply in the Australian context.

In addition to the resources required by AMOSS project team and investigators, there was an added impost on maternity staff - who spent considerable time undertaking clerical work to progress AMOSS applications - in addition to the HREC staff themselves. This burden is reflected in the increasing numbers of HRECs that charge application-related fees of up to \$550: an unnecessary level of cost recovery with true single application processing.

The current processes compromise efficient and successful implementation of public health research without providing a corresponding benefit for research participants. On the contrary, it has been argued that overly regulated ethical review processes on minimal risk research can produce inconsistent decisions and retard quality improvement(17). The degree to which one HREC approach is consistent with others provides a significant indication of effectiveness(18).

A simpler process of ethics/governance approval would allow research such as AMOSS to improve efficiencies and better achieve research objectives. A more centralised system that involves a consistent administrative process as outlined by Fitzgerald and Phillips(19) benefits all research stakeholders. Underpinned by enhanced reciprocities and transparent guidelines, such a system would promote the features that HoMER aims to provide: accountability and efficacy whilst retaining the primacy of protecting research participants.

\section{Contrasting models of low-risk multi-centre research}

The NZ and UKOSS models provide instructive contrasts in how ethics/governance approval processes for low-risk studies can be streamlined and implemented without risk to patients' rights and confidentiality.

The single national ethics approval process enabled NZ sites to begin data collection from the beginning of 2010. In contrast, only $38 \%$ of Australian sites had completed ethics approval by this stage. The UK Obstetric Surveillance System was launched in 2005(20). Applications for ethics approval of the six initial studies and the system itself (covering approximately 760,000 births) were considered by a single designated research ethics committee. Complete participation by all hospitals with consultant-led maternity units in the UK was achieved within three months of the system launch, and less than a year from commencement of program planning(21). (However, other UK researchers have not found the research governance process as streamlined as UKOSS)(22-24)

Other countries grapple with similar issues as Australia, with varying approaches and policies. A review of research governance processes in Canada found fragmented and uneven approaches(25), with researchers noting that the administrative hurdles required for multicentre ethical reviews did not contribute toward the protection of research subjects(26). Under a revised policy released 2010, arrangements emphasise stronger reciprocity of reviews(26). In the USA, the Office for Human Research Protections (OHRP) outlines strategies to avoid duplication in ethics applications for cooperative research. However, the articulation of this policy is uneven and subject to various interpretations $(27,28)$.

The required steps undertaken by the AMOSS study demonstrates the need for more extensive efficiencies. We welcome the further development of HoMER and its application to 
public health research. However, there remains a high level of inconsistency in the implementation of ethical/governance reviews for multi-centre population low-risk research.

\section{Update on HoMER implementation in Australia}

Changes to the ethics/governance review process in Australia have been steadily implemented over the last few years. Because AMOSS was established during this period of significant reform, and due to the length of time taken to cover the large number of research sites, we have been in a position to monitor the implementation of changes that address some barriers to multi-centre low-risk research.

Key changes to HoMER implemented during AMOSS' establishment have included:

- Review of all multi-centre research studies conducted in Queensland Health facilities by a single certified HREC since July 2010(29).

- Implementation of modified processes to improve the NSW review of multi-centre research, including a requirement for NSW HRECs to establish an expedited process for low/negligible risk research and benchmarks for timeliness of ethical review and authorisation(30).

- Establishment of a centralised system for single ethical review of multi-centre research in Victoria (currently limited to clinical trials, and not including low-risk population or surveillance studies)(31).

- A discussion paper released late 2010, calling for feedback on good practice in governance in multi-centre human research that has undergone a single ethical review(32).

Whilst reform is evident there is still some way to go before a robust national surveillance system can be established without excessive ethical review duplication.

\section{Recommendations}

Based on our findings, a number of strategies could significantly reduce the burden on resources whilst maintaining the principles underlying HoMER - efficiency, authority, respect, verifiability and compliance. These suggested measures include:

- Clearer and more transparent guidelines regarding the steps and requirements of ethics and governance applications for both HREC and researchers, such as those introduced by Queensland(29) and outlined in the UK(33).

- Universal acceptance of electronic submissions of ethics applications.

- Simplified site governance endorsements that accept hospital support in electronic (email) format in addition to letters of support and SSAs.

- A single version annual progress/final report circulated to the Lead HREC and research governance offices of participating sites.

\section{Conclusion}

National public health research is critical to understand the burden of rare, severe maternal morbidity and for the development of evidence-based tools to address these conditions. The information derived from AMOSS, a relatively low resource study, cannot easily be obtained through any other methodology. 
However, the ethics/governance review process required by AMOSS resulted in a prolonged setup period of almost two years without any demonstrable benefits to research participants.

These application requirements were not aligned to the guidelines and principles of HoMER. The process has been variable and repetitive for researchers, hospitals and ethics review committees alike. The resultant burden on resources challenges the ability of researchers to undertake evidence-based practice in the area of rare, serious obstetric disorders.

The AMOSS project was implemented during a period of considerable change in the way ethics/governance reviews are addressed in Australia. It is hoped that progressive development will achieve the intent and aims of HoMER to provide a significantly more streamlined process than was required by AMOSS. A simplified, uniform approach will greatly enhance project efficiencies. Escalated implementation of a true single ethics review application for multi-centre low-risk research at a national level, together with simplified site governance review processes, is a critical priority.

\section{Acknowledgements}

Thank you to the obstetricians, midwives, data coordinators, maternity units, risk managers, HREC staff, professional Colleges and others who have supported AMOSS to date with their tireless commitment to helping establish AMOSS and participating in the research.

We gratefully acknowledge NHMRC funding for our research ("The Australasian Maternity Outcomes Surveillance System: improving the safety and quality of maternity care in Australia"; grant number 510298), without which the research would not be possible. 


\section{References}

1. National Health and Medical Research Council (NHMRC). Harmonisation of Multicentre Ethical Review (HoMER). Canberra, ACT: NHMRC Publications; 2010; Available from: http://www.nhmrc.gov.au/health_ethics/homer/index.htm.

2. National Health and Medical Research Council (NHMRC). Harmonisation of Multicentre Ethical Review (HoMER) enabling system. Canberra, ACT: NHMRC Publications; 2008.

3. Studdert DM, Vu, T.M., Fox, S.S., Anderson, I.P., Keeffe, J.E.,Taylor, H.R. Ethics review of multisite studies: the difficult case of community-based Indigenous health research. Med J Aust. 2010;192(5):275-80.

4. Kidd T, Marks G, Bye P, Wainwright C, Robinson P, Rose B, et al. Multi-centre research in Australia: Analysis of a recent National Health and Medical Research Councilfunded project. Respirology. 2009;14(7):1051-5.

5. Thompson S, Sanfilippo, FM., Briffa, TG., Hobbs M. Towards better health research in Australia - a plea to improve the efficiency of human research ethics committee processes. Med J Aust. [letter to the editor]. 2009;190(11):652.

6. $\quad$ Shelby-James T, Agar, M.R., Currow, D.C. A case study evaluation of ethics review systems for multicentre clinical trials. Med J Aust. 2010;192(5):292-3.

7. Fraser HE, Martlew, A.E., Frew, D.J. Model for a single ethical and scientific review of multicentre research in New South Wales. Med J Aust. 2008;187(1):7-8.

8. Jaffe A, Strachan, R.E., Williams, K.J. Consent in paediatric research: an evaluation of the guidance provided in the 2007 NHMRC National statement on ethical conduct in human research. Med J Aust. 2008;189(6):347-8.

9. Pollock W, Sullivan E, Nelson S, King J. Capacity to monitor severe maternal morbidity in Australia. The Australian and New Zealand Journal of Obstetrics and Gynaecology. 2008;48(1):17-25.

10. Australasian Maternity Outcomes Surveillance System. Australasian Maternity Outcomes Surveillance System Sydney, NSW: Perinatal and Reproductive Epidemiology Research Unit (PRERU); 2010 [updated 8/6/2010; cited 2010]; Available from: http://www.amoss.com.au.

11. National Health Committee; Medical Research Council; Australian Research Council; Australian Vice-Chancellors. National Statement on Ethical Conduct in Human Research. Canberra, ACT: NHMRC Publications; 2007.

12. National Health and Medical Research Council (NHMRC). Australian Code for the Responsible Conduct of Research. Canberra: Australian Government NMHRC, ARC, Universities Australia. 2007.

13. Pittman K. Streamlining scientific and ethics review of multi-centre health and medical research in Australia: Report to the NHMRC - July 2007. Melbourne, Vict. 2007. 14. Victorian Department of Health (VDOH). National Ethics Application Form and the Victorian Specific Module. Melbourne 2010; Available from: http://www.health.vic.gov.au/ethics/single/neaf_vsm.htm.

15. National Health and Medical Research Council (NHMRC). Australia Online Forms for Research. 2010; Available from: https://www.ethicsform.org/au/SignIn.aspx.

16. McLintock, C. Personal communication, January 2010.

17. Kim S, Ubel, P., De Vries, R. Pruning the regulatory tree. Nature. 2009;457(7229):534-5.

18. Bloom GS, Frew, D. Regulation of research through research governance: within and beyond NSW Health. N S W Public Health Bull. 2009;19(11-12):199-202.

19. Fitzgerald MH, Phillips, P.A. Centralized and Non-Centralized Ethics Review: A Five Nation Study. Account Res. 2006;13(1):47 - 74.

20. Knight M, Spark, P., Pierce, M., Kayem, G., Kurinczuk, J.J., and Brocklehurst, P., on behalf of UKOSS,. United Kingdom Obstetric Surveillance System (UKOSS) Annual Report 2010. Oxford, UK: National Perinatal Epidemiology Unit (NPEU). 2010. 
21. Knight M, (Head of UKOSS United Kingdom Obstetric Surveillance System), Personal communication. United Kingdom Obstetric Surveillance System (UKOSS). 2010.

22. Whitehead P, Fellows, K., Sprigg, N., Drummond, A. Research governance. There is nothing streamlined about the system. BMJ (Int Ed). 2010;341(c5633):794.

23. Thompson AGH, France, E.F. One stop or full stop? The continuing challenges for researchers despite the new streamlined NHS research governance process. BMC Health Serv Res. 2010;10(124):1-8.

24. Fudge N, Redfern, J., Wolfe, C., McKevitt, C. Streamlined research governance: are we there yet? BMJ (Int Ed). 2010;341(4625):635-7.

25. The Experts Committee for Human Research Participant Protection in Canada. Moving Ahead: Final Report. Ottawa, Canada. 2008.

26. Panel on Research Ethics (PRE). TCPS 2-2nd edition of Tri-Council Policy Statement: Ethical Conduct for Research Involving Humans. Ottawa, Canada: Canadian Institutes of Health Research; Natural Sciences and Engineering Research Council of Canada; and Social Sciences and Humanities Research Council of Canada. 2010.

27. Office for Human Research Protections (OHRP). Guidance on Engagement of Institutions in Human Subjects Research. Washington DC USA: US Department of Health and Human Services; 2008 [cited 2010]; Available from:

http://www.hhs.gov/ohrp/policy/engage08.html.

28. Office for Human Research Protections (OHRP). International Compilation of Human Research Protections: 2010 Edition. Washington: U.S. Department of Health and Human Services. 2010.

29. Office of Health Medical Research (OHMR). Model for Single Ethical Review of Multi-centre Research for Queensland Health. Brisbane: Queensland Health. 2010.

30. NSW Department of Health. New and modified processes for research ethics and governance in NSW Public Health Organisations: consultation feedback report. Sydney, NSW: Research, Ethics and Public Health Training, NSW Department of Health. 2010.

31. Consultative Council for Human Research Ethics (CCHRE). Streamlining ethical review. Melbourne, Victoria: Public Health Branch, Rural \& Regional Health \& Aged Care Services Division of the Victorian State Government, Department of Health, Australia; 2010 [cited 2010]; Available from: http://www.health.vic.gov.au/cchre/streamlining.htm.

32. National Health and Medical Research Council (NHMRC). Discussion Paper: Understanding Research Governance of Multi-centre Human Research. Canberra ACT: NHMRC Publications; 2010. p. 1-27.

33. National Patient Safety Agency (NPSA). Is your project research? London UK: National Research Ethics Service; 2009 [cited 2010]; Available from: http://www.nres.npsa.nhs.uk/applications/apply/is-your-project-research/. 


\section{Table 1 AMOSS ethics/governance application process}

\begin{tabular}{|c|c|c|}
\hline & Steps & Comments \\
\hline 1 & $\begin{array}{l}\text { Establish in principle approval from maternity } \\
\text { unit and/or clinical/obstetric services }\end{array}$ & $\begin{array}{l}\text { In principle approval process varies enormously } \\
\text { according to site, region, and internal policies. }\end{array}$ \\
\hline 2 & Identify ethics and governance body & $\begin{array}{l}\text { Confusion at hospital level about which was the } \\
\text { correct assessing body }(n=4) \text {. }\end{array}$ \\
\hline 3 & $\begin{array}{l}\text { Determine the type of research under which } \\
\text { AMOSS assessed }\end{array}$ & $\begin{array}{l}\text { AMOSS was assessed as a quality assurance (QA) } \\
\text { project }(n=6) \text {; expedited or low-risk }(\mathrm{n}=11) \text {; required } \\
\text { a 'more than low-risk' application (NEAF, Vic } \\
\text { Module One or other) }(\mathrm{n}=32) \text {; or was endorsed under } \\
\text { an existing ethics application }(\mathrm{n}=212) \text {. }\end{array}$ \\
\hline 4 & $\begin{array}{l}\text { Determine the documentation requirements - } \\
\text { which forms? How many copies? Electronic } \\
\text { only? Hard copy only? Electronic and hard } \\
\text { copy? How submitted? Deadlines? }\end{array}$ & $\begin{array}{l}\text { Varied requirements: up to } 26 \text { hard copies of ethics } \\
\text { applications were required by some HRECs ( } 26 \\
\text { copies = } 2444 \text { pages printouts); others accepted } \\
\text { electronic copy only; others mixed. }\end{array}$ \\
\hline 5 & Complete research governance applications & $\begin{array}{l}\text { Varied processes according to HREC/Clinical } \\
\text { governance. These included SSA or other site } \\
\text { governance applications }(\mathrm{n}=135) \text {; and letter or email } \\
\text { of support ( } \mathrm{n}=139) \text {. }\end{array}$ \\
\hline 6 & $\begin{array}{l}\text { Establish correct personnel to provide site } \\
\text { support for governance. Obtain signed site } \\
\text { endorsements. }\end{array}$ & $\begin{array}{l}\text { Much variation in personnel, process, submission } \\
\text { method and time taken to obtain site endorsement } \\
\text { (range } 1-111 \text { days). }\end{array}$ \\
\hline 7 & $\begin{array}{l}\text { Respond to queries regarding ethics and } \\
\text { governance applications }\end{array}$ & $\begin{array}{l}\text { Much duplication of queries and responses, and } \\
\text { conversely much variation in interpretation. }\end{array}$ \\
\hline 8 & Approval obtained & $\begin{array}{l}\text { Depending on HREC staff resources and current } \\
\text { burden, a letter of approval could be delayed by up to } \\
\text { a month after it had been approved by HREC } \\
\text { committee. }\end{array}$ \\
\hline 9 & $\begin{array}{l}\text { (Queensland) Submit request for Public Health } \\
\text { Act release of data }\end{array}$ & $\begin{array}{l}\text { This step is integrated into other states' governance } \\
\text { applications. }\end{array}$ \\
\hline 10 & Annual reporting & $\begin{array}{l}\text { Required by HRECs and individual clinical } \\
\text { governance committees. }\end{array}$ \\
\hline 11 & $\begin{array}{l}\text { Monitor length of ethics approval and re-apply } \\
\text { where required }\end{array}$ & $\begin{array}{l}9 \text { months' ethics validity }(n=1) \text {; three years' validity } \\
(n=7) \text {; the balance gave validity to either end of } 2014 \text {, } \\
\text { or no expiry noted. }\end{array}$ \\
\hline
\end{tabular}


Table 2: AMOSS: ethical and governance review application processes (Australian State jurisdiction and New Zealand), with UK comparison

\begin{tabular}{|c|c|c|c|c|c|c|c|c|c|c|c|}
\hline & $\begin{array}{l}\text { NSW } \\
\mathrm{n}=74\end{array}$ & $\begin{array}{l}\text { VIC } \\
\mathrm{n}=64\end{array}$ & $\begin{array}{l}\text { QLD } \\
\mathrm{n}=49\end{array}$ & $\begin{array}{l}\text { SA } \\
\mathrm{n}=26\end{array}$ & $\begin{array}{l}\text { WA } \\
\mathrm{n}=34\end{array}$ & $\begin{array}{l}\text { TAS } \\
\mathrm{n}=6\end{array}$ & $\begin{array}{l}\text { ACT } \\
\mathrm{n}=3\end{array}$ & $\begin{array}{l}\text { NT } \\
n=5\end{array}$ & $\begin{array}{l}\text { Total } \\
\text { Australia } \\
\mathbf{n = 2 6 1}\end{array}$ & $\begin{array}{l}\text { Total NZ } \\
\text { n=20 District } \\
\text { Health } \\
\text { Boards } \\
\text { (DHBs) }\end{array}$ & $\begin{array}{l}\text { Total UK } \\
n=226\end{array}$ \\
\hline Ethics & \multicolumn{11}{|c|}{ 'How do we prevent harm to participants?' } \\
\hline $\begin{array}{l}\text { Discrete full or } \\
\text { expedited applications } \\
\text { - NEAF } \\
\text { - (Vic) Module One } \\
\text { - Expedited (low-risk) } \\
\text { application }\end{array}$ & 2 & 20 & 12 & 1 & 3 & 1 & 2 & 1 & $\begin{array}{l}\text { Full ethics } \\
\text { application } \\
\mathrm{n}=31 \\
\text { Expedited or } \\
\text { low risk } \\
\text { ethics } \\
\text { application } \\
\mathrm{n}=11\end{array}$ & $\mathrm{n}=1$ & $\mathrm{n}=1$ \\
\hline Site Governance & \multicolumn{11}{|c|}{ 'Does the hospital/maternity unit support the research; and does it have the resources?' } \\
\hline $\begin{array}{l}\text { Site approvals: SSA or } \\
\text { hospital governance } \\
\text { forms }\end{array}$ & 53 & 33 & 24 & 0 & 6 & 3 & 3 & 1 & $\mathrm{n}=123$ & $\mathrm{n}=1$ & $\mathrm{n}=1$ \\
\hline $\begin{array}{l}\text { Letters/emails of } \\
\text { support }\end{array}$ & 16 & 33 & 27 & 26 & 28 & 3 & 0 & 4 & $\mathrm{n}=137$ & N/A & N/A \\
\hline $\begin{array}{l}\text { Assessed as Quality } \\
\text { Assurance }\end{array}$ & \multicolumn{11}{|c|}{ "Monitor, evaluate or improve the quality of health care delivered by a health care provider" } \\
\hline & 0 & 0 & 0 & 0 & 6 & 0 & 0 & 0 & $\mathrm{n}=6$ & & \\
\hline PHA Act (Qld only) & \multicolumn{11}{|c|}{ "Is it OK to release the data from the hospital?" } \\
\hline $\begin{array}{l}\text { Separate requests to } \\
\text { data custodians }\end{array}$ & 0 & 0 & & 0 & 0 & 0 & 0 & 0 & $\mathrm{n}=19$ & N/A & N/A \\
\hline
\end{tabular}


Table 3: Resource burden in the ethics/governance application process: June 2009 - October 2010 (with UK comparison)

\begin{tabular}{|c|c|c|c|}
\hline & AUSTRALIA & NEW ZEALAND & $\begin{array}{c}\text { UNITED } \\
\text { KINGDOM } \\
\text { (UK Obstetric } \\
\text { Surveillance } \\
\text { System UKOSS) }\end{array}$ \\
\hline $\begin{array}{l}\text { AMOSS project } \\
\text { team }\end{array}$ & $\begin{array}{l}809 \text { logged phone calls; } \\
1,422 \text { logged emails; } \\
1,024 \text { logged miscellaneous notes and } \\
\text { communications relating to } \\
\text { ethics/governance applications with } \\
\text { maternity units and HRECs/governance } \\
\text { bodies* } \\
\text { (*audited June } 2009 \text { - December } 2010 ; \text { does } \\
\text { not include time spent by the clinical } \\
\text { coordinator for Victoria and Tasmania) }\end{array}$ & & \\
\hline $\begin{array}{l}\text { AMOSS } \\
\text { investigators }\end{array}$ & $\begin{array}{l}\text { Administrative time spent signing and } \\
\text { returning ethics applications. }\end{array}$ & & \\
\hline Maternity units & $\begin{array}{l}\text { Time spent responding to AMOSS queries } \\
\text { and follow-ups about ethics related } \\
\text { applications and issues }\end{array}$ & & \\
\hline $\begin{array}{l}\text { HRECs; other } \\
\text { ethics and } \\
\text { governance } \\
\text { bodies }\end{array}$ & $\begin{array}{l}\text { Time involved in processing ethics } \\
\text { applications already processed and approved } \\
\text { on other sites }\end{array}$ & & \\
\hline $\begin{array}{l}\text { Resource burden } \\
\text { - person hours } \\
\text { AMOSS project } \\
\text { team and } \\
\text { investigators }\end{array}$ & $\begin{array}{l}\text { Estimated 2,556 hours January } 2009 \text { - } \\
\text { December } 2010\end{array}$ & $\begin{array}{l}\text { Total estimated } \\
\text { time ten hours (per } \\
\text { NZ AMOSS } \\
\text { coordinator) }\end{array}$ & $\begin{array}{l}\text { Total estimated ten } \\
\text { days (per UK } \\
\text { Clinical } \\
\text { coordinator) }\end{array}$ \\
\hline
\end{tabular}


Figure 1 HoMER concept diagram: Single ethical review(2)

\section{Single Ethical Review}

- Coordinating Investigator $(\mathrm{Cl})$ submits an ethics application to one HREC that is using certified ethical review processes.

- One HREC conducts an ethical review of the research proposal (i.e. single ethical review occurring for one research proposal).

- $\mathrm{Cl}$ receives the response of one HREC.

- Principal Investigators at each participating institution provide the outcome of the single ethical review to their respective institution.

Sin . Each participating institution uses the outcome of the single ethical review and their site-specific research governance information to determine whether or not research will commence at their institution.

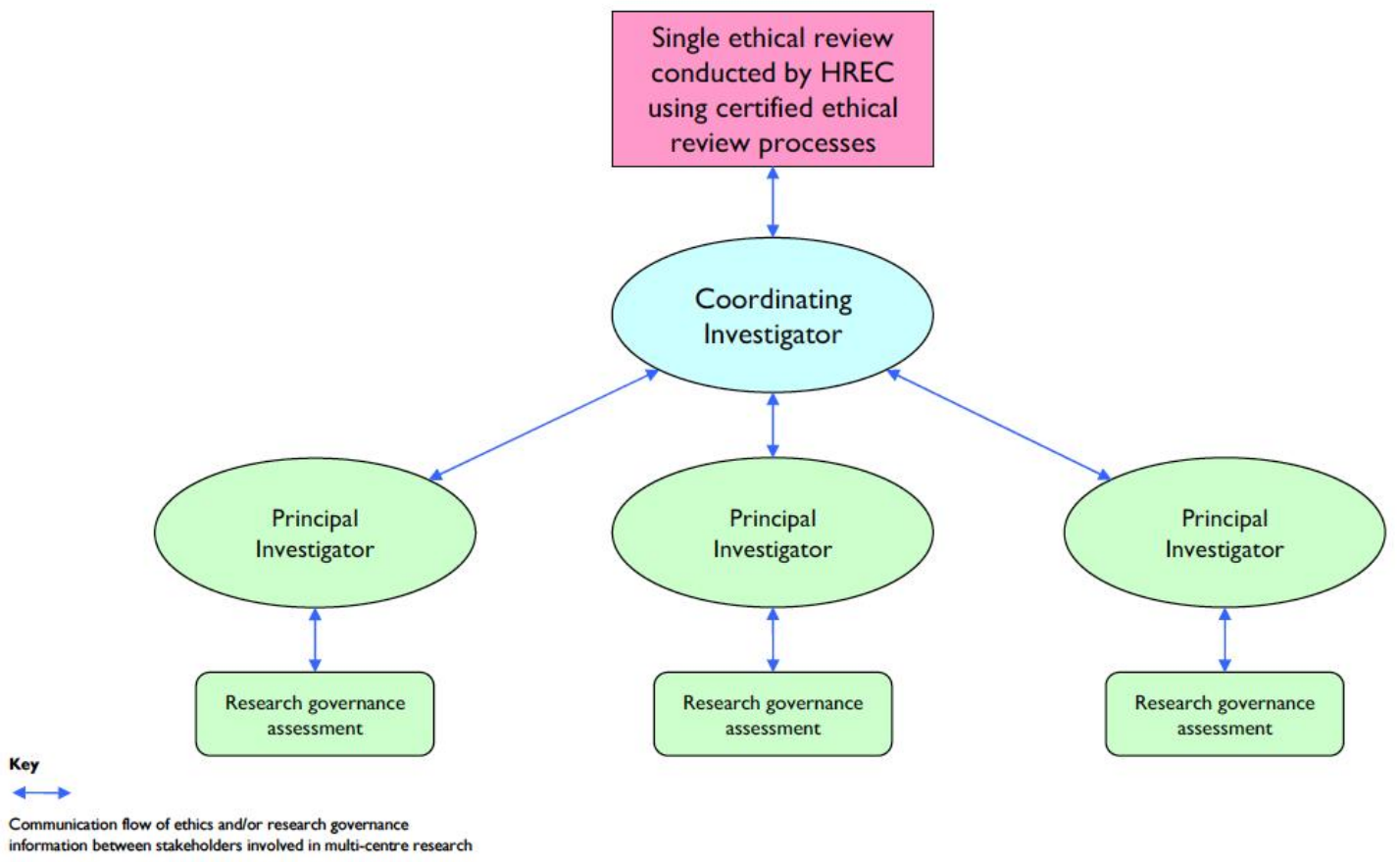


Figure 2: Ethics/governance application process

\section{A) AMOSS project}

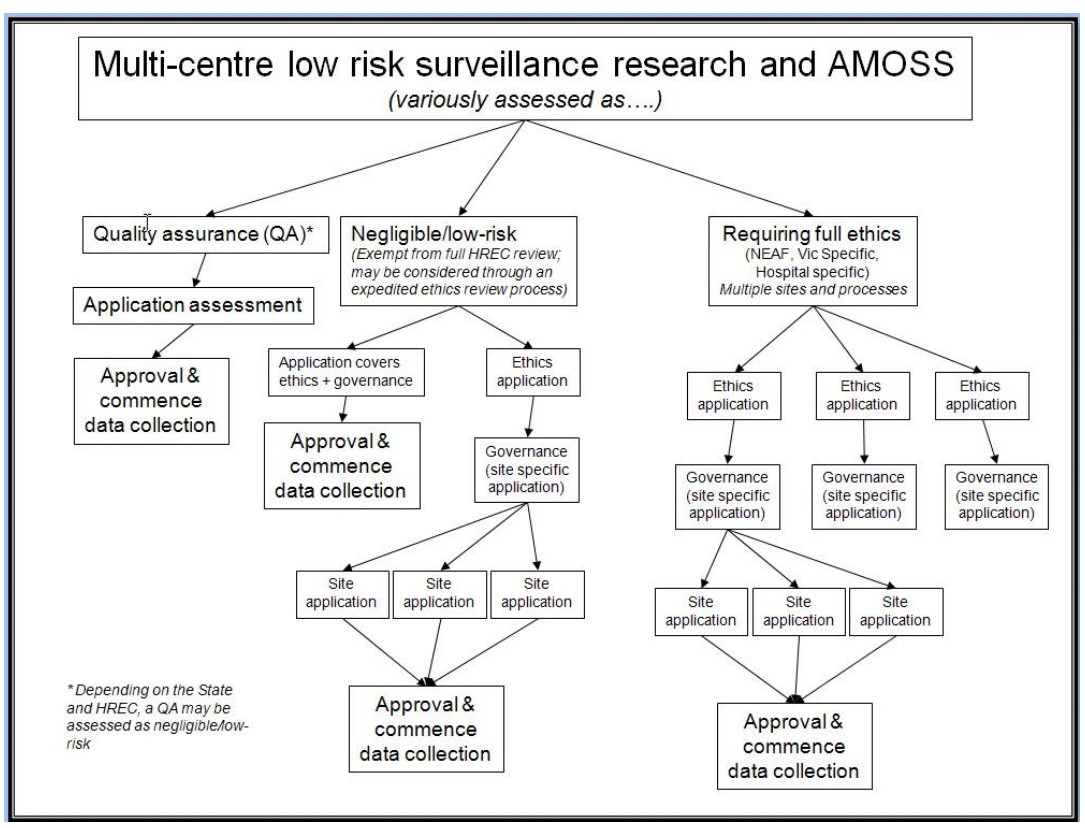

\section{B) A suggested alternate model}

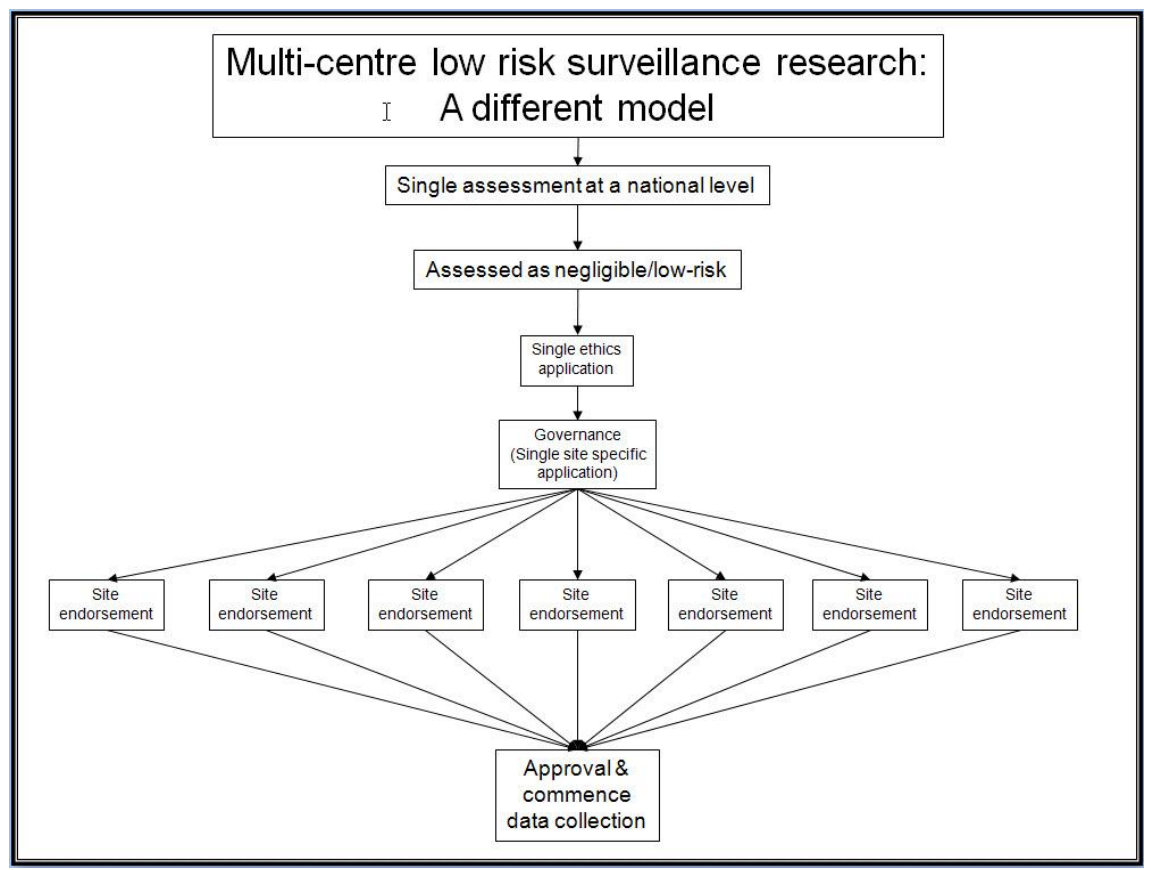

